http://dx.doi.org/10.14393/HeP-v30n57-2017-2

\title{
A TRAMA TÊXTIL DE VILLA PLATINA: PROFISSÕES DO VESTUÁRIO NO SERTÃO DE MINAS*
}

\author{
Maristela Novaes** \\ Noé Freire Sandes ***
}

RESUMO: Este artigo analisa a presença de profissionais do vestuário (fiandeiras, tecelãs, costureiras, alfaiates, comerciantes etc.) no município de Villa Platina, tendo como fonte documental os livros que compõem o Recenseamento Municipal de 1904. Essa vila localiza-se na região do Triângulo Mineiro, antigo "Sertão da Farinha Podre", Minas Gerais. O objetivo é compreender o contexto cultural dessa vila e a relação dessa sociedade com seu sistema de vestuário e com o comércio direcionado a esse ramo. Para isso, investigamos as origens, o nível de alfabetização, as relações de parentesco e os locais de residências dos profissionais e suas relações com o aprendizado e com o exercício dessa profissão. Nessa sociedade já era visível a presença de imigrantes introduzindo novas técnicas de costura, um dos fatores a colaborar para a redefinição da tradição da manufatura de roupas local. Como procedimento teórico-metodológico, a investigação parte do entrecruzamento de várias fontes numa perspectiva dialética para situar historicamente a vila e as atividades dos profissionais do vestuário.

* Esse artigo se vincula ao projeto de pesquisa de doutorado em História, La costruzione di uno spencer Liberty nei confini di Minas, orientado pela Profa Maria Giuseppina Muzzarelli, professore ordinário no Dipartimento di Storia Cultura Civiltà da Università di Bologna, Itália

** Mestre em Cultura Visual pela Faculdade de Artes Visuais da UFG e doutoranda no programa de pós-graduação, Dottorato di Ricerca in Storia Cultura Civiltà, com endereço em História, na Università di Bologna-Itália, e professora no Curso de Design de Moda da Universidade Federal de Goiás, Brasil.

${ }^{* * *}$ Professor titular da Faculdade de História da Universidade Federal de Goiás, pesquisador do do CNPq. 
PALAVRAS-CHAVE: Profissões do vestuário. Imigração. Modernidade. Villa Platina.

\begin{abstract}
This article analyzes the presence of garment workers (spinners, weavers, seamstresses, tailors, etc.) in the municipality of Villa Platina. It has the 1904 county census as the primary source of investigation. This village is located in the Triângulo Mineiro region, former "Hinterland of rotten flour", Minas Gerais. The objective is to understand the cultural context of this village and the relationship of this society with the clothing production and commerce. Therefore, we investigate the origins, the level of literacy, kinship relations and the residential sites of professionals, as well as their relation with learning and the pursuit of this profession. In this society it was already visible the presence of immigrants introducing new sewing techniques, one of the factors that contributed to the redefinition of the tradition of local clothing manufacturing. The research begins with a description of the census and relates it with other sources, with a dialectic perspective, to better situate historically the village and the clothing professional's activities.
\end{abstract}

KEY-WORDS: Clothing professions. Immigration. Modernity. Villa Platina.

\title{
Desdobrando o tecido
}

Villa Platina ${ }^{1}$ foi uma vila da região do Triângulo Mineiro, antigo "Sertão da Farinha Podre", interior de Minas Gerais, Brasil. Assim foi nominada de 1901 a 1915. Seguindo a hierarquia dada aos diferentes núcleos de povoamentos no Brasil, primeiro ela foi um povoado formado no entorno da Capela de São José do Tijuco, esta fundada em 1832 pelo padre Antônio Dias de Gouveia, nas terras a ela doadas em 1820 pelos sesmeiros José da Silva Ramos

1 Adotamos o uso dos nomes de localidades e de pessoas como aparecem no documento. 
e Joaquim Antônio de Morais. Em 1839, foi criada a freguesia de São José do Tijuco, passando à condição de distrito do mesmo nome. De distrito, em 16 de setembro de 1901, pela Lei Estadual $\mathrm{n}^{\circ} 319$, foi instituído o Município de Villa Platina, com território desmembrado do Município do Prata, ao qual era subjugado. Em 1915, a vila recebeu foros de cidade, tal como o distrito e o município, com o nome de Ituyutaba.

Vila foi uma condição e Villa Platina um nome provisório, um nome de passagem. Doze anos após a proclamação da República Federativa do Brasil, essa é uma sociedade em transição. A vila, bem como boa parte do território brasileiro, vivia a tensão de adequar-se aos valores republicanos, em meio às tradições herdadas do império.

Esse estudo utiliza como fonte primária a documentação oficial referente aos livros que compõem o Recenseamento Municipal de 1904 de Villa Platina (ITUIUTABA, 1904) e tem como objetivo compreender seu contexto sociocultural e a relação dessa sociedade republicana, especificamente mineira, com seu sistema de produção de vestuário. Como procedimento teóricometodológico, realizamos o entrecruzamento de várias fontes para compreendermos: 1 . a relação entre o contexto cultural presente nessa vila, sua articulação com comércio do vestuário e o mesmo com uma perspectiva global; 2 . como se efetivava a formação dos profissionais do vestuário por intermédio da cultura familiar e pela escolarização institucional; e 3. a inserção do imigrante nessa sociedade e sua contribuição às transformações das práticas das manufaturas de roupas locais.

Deste modo, procuramos identificar no documento as qualificações e ou profissões ligadas à tecelagem e à manufatura de roupas, tais como: fiandeiras, tecelãs, costureiras, alfaiates, assim como comerciantes - de tecidos, aviamentos, livros técnicos e revistas de moda - que ofereciam matéria prima, além de informações técnicas e de moda, fomentando a atividade.

\section{A urdidura: o espaço rural}

Villa Platina localiza-se no vale do Rio Paranaíba, que faz parte da segunda maior bacia hidrográfica do Brasil: a bacia do Prata ou bacia Platina. Um dos principais rios desta bacia é o Rio 
Paraná, formado pela confluência dos rios Paranaíba e Grande (Fig. 1). Antes dessa confluência, que forma o "nariz" do Triângulo Mineiro, numa complexa rede hidrográfica, o Rio Paranaíba recebe as águas do Rio da Prata. Este, por sua vez, recebe as do Rio Tijuco. Rio da Prata e Rio Tijuco formam um triângulo. Dois córregos formam o ribeirão do Carmo que deságua no Rio Tijuco. É na confluência desses dois córregos, o Piratininga e o Sujo, que se assenta a vila recenseada acomodada no que seria chamado de Chapadão de São Vicente. Serras emergem do chapadão: a de São Lourenço de sul a sudoeste; o morro do Bahú e o do Bahuzinho ao norte; e a nordeste o morro da Mamona. A visualização desse relevo e da sua rede hidrográfica, registrada no mapa do Município de Ituyutaba (Fig. 1), tem relevância para a compreensão desse espaço, uma vez que nomeiam as localidades circundantes: fazendas e latifúndios. Além disso, à esquerda, na Figura 1, se sobrepõe o pequeno mapa que nos permite visualizar a situação desse município no Estado de Minas Gerais.

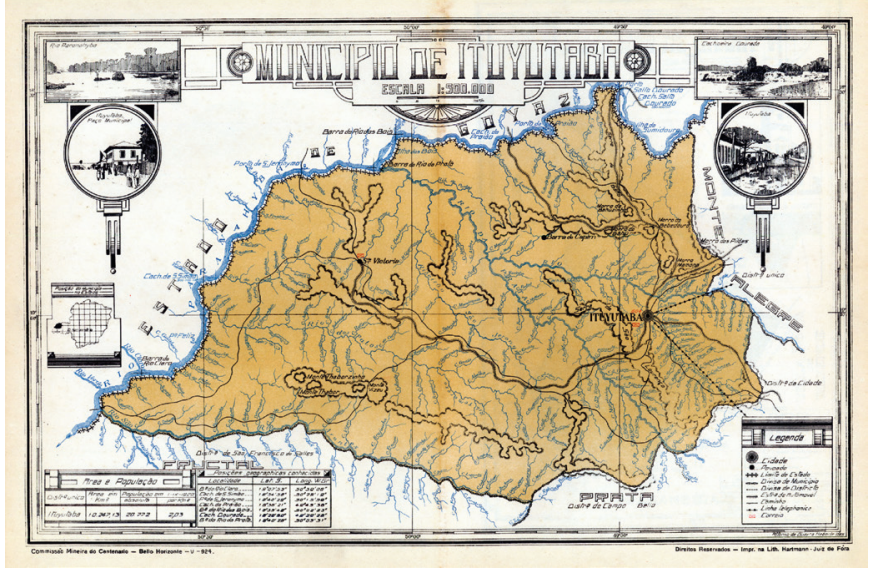

Fig. 1 - Mapa do município de Ituyutaba, antiga Villa Platina, 1927.

Fonte: Album Chorographico $1927 .^{2}$

2 O mapa do município de Ituiutaba adotado neste trabalho faz parte do Album Chorographico, que foi produzido no contexto de comemoração do Centenário de Independência do Brasil (1822-1922) e publicado em 1927. MINAS GERAIS. Album Chorographico. 1927. Disponível em: <http://www. albumchorographico1927.com.br>. Acesso em: 15 jul. 2015. 
O município de Villa Platina, quando de sua criação, foi composto pelos distritos de São José do Tijuco e N. Sra . do Rosário da Boa Vista do Rio Verde (Monjolinho). Prata e Villa Platina disputaram o espólio dessa área, a partir da criação da vila, e, em 1911, pela Lei Estadual de 30 de agosto, o distrito de Boa Vista do Rio Verde foi transferido do Município de Villa Platina (Ituyutaba) para o Município do Prata e sua sede para a povoação de Campo Bello ${ }^{3}$. Publicações de Villa Platina no Almanak Laemmerts (SAUER, 1904-1909), no período que vai de 1904 a 1909, especificavam uma superfície de 20.000 quilômetros quadrados para o município, sendo este coberto por $1 / 5$ de matas ${ }^{4}$.

É nessa área que se espalha a população rural organizada em latifúndios. Essa superfície era, originalmente, coberta por florestas virgens, capoeiras e campos de criar. Na raiz do seu povoamento, os imensos latifúndios ocuparam essas terras com a criação extensiva de gado vacum e o cultivo de grãos numa prática de agricultura de subsistência em que o excedente era vendido nos centros urbanos mais próximos às áreas de produção (TEIXEIRA, 1953). Nessas unidades de produção rural, além dos mantimentos para sustento da família, como arroz, milho, feijão, rapadura, café, produzia-se os veículos de tração animal, as arreatas, os chapéus, as alpercatas de couro cru, os materiais para habitações etc. Tudo era utilizado no regime de economia da abastança em que as "casas de negócios" das vilas obtinham pouca vantagem (CHAVES, 1953, p. 46).

3 Para esta síntese, ver "Histórico do Município" de Ituiutaba, Prata e Campina Verde em IBGE Cidades. BRASIL. Instituto Brasileiro de Geografia e Estatística (IBGE). Históricos dos censos. Censos demográficos. Disponível em: <http://memoria.ibge.gov.br/pt/sinteses-historicas/historicos-dos-censos/ censos-demograficos>. Acesso em: 17 jun. 2105.

Os dados são ambíguos, uma vez que a cidade do Prata anuncia em 1904 uma área de 20.000 quilômetros para os dois municípios. Em 1909, Vila Platina anuncia a mesma área para seu município. SAUER, A. Almanak Laemmert: Almanak Administrativo, Mercantil e Industrial do Rio de Janeiro: Estado de Minas Geraes. Rio de Janeiro: Companhia Typographica do Brazil, 1904. p. 1259; p. I-103. Disponível em: <http://memoria.bn.br>. Acesso em: 20 set. 2015. 
O vestuário não fugia a essa regra. Na fazenda do Salto, propriedade do Major Francisco José de Carvalho ${ }^{5}$, ainda no Segundo Império, um tear de madeira era usado para tecer os fios de algodão colhido na lavoura e para preparar o tecido caseiro, nominado de "pano tecido cá", sendo este destinado a confecção de roupas para os escravos, redes, colchas e também roupas de serviço para homens e mulheres, comprovando que essas unidades de produção se ocupavam também da tecelagem e da manufatura de roupas.

Assim como a urdidura forma a estrutura base do tecido (DONNANNO, 2011), são as atividades agropastoris as bases do povoamento do "Sertão da Farinha Podre". Segundo Chaves (1953, p. 45), foi o sertanejo, "com sua família, se sucedendo pelos anos afora, quem permaneceu na liderança da ação civilizadora, criando fazendas, subdividindo nos inventários os imensos latifúndios, empurrando com seu braço e seu sangue, em cada descendência, a linha divisória do sertão". Ao longo do século $\mathrm{XIX}$, as áreas ocupadas pelos nativos índios Caiapós seriam expropriadas em função da ocupação pelo sertanejo, descendente de portugueses, expandindo o povoamento com suas práticas de produção rural. Assim, a importância da economia rural, para essa sociedade na primeira década do século XX, pode ser comprovada pelo anúncio da administração municipal de Villa Platina no Rio de Janeiro (SAUER, 1909, p. I-103), onde se lê que as maiores fontes da renda do município são a criação de gado vacum, a criação de suíno e a produção de arroz.

A vida ali era basicamente rural, e assim o foi até por volta de 1930 (TEIXEIRA, 1953). Segundo Teixeira (1953, p. 182), sua população espalhava-se pela extensão do município e "a sede era apenas procurada para os serviços de assistência religiosa, médico-fármaco-dentária, quando não comercial, forense, social

5 Major Carvalho, proprietário do latifúndio que compreendia terras que começavam nos morrinhos do Prata e alcançavam a barra do São Vicente. CHAVES, Petronio Rodrigues. A loja do Osório. Ituiutaba: Edição do autor, 1984. 
e política". Sendo uma população eminentemente católica, a missa na lgreja de São José do Tijuco aos domingos e as festas religiosas e cívicas eram veículos de convergência social.

\section{A trama: o espaço urbano}

1904, data do recenseamento em analise, é o $21^{\circ}$ ano de trabalho, na "Matriz de São José do Tijuco, Diocese de Goyas, Estado de Minas Gerais"6, daquele que viria a ser chamado de o padre urbanista e o recenseador: Pe. Ângelo Tardio Bruno, italiano, napolitano de origem. Em 1883, quando o padre ali chegou, o arraial era um descampado com a igreja no centro e alguns casebres ao redor. Tudo era coberto de palhas: casebres e igreja. O padre, que saiu da Itália determinado a catequizar índios (TEIXEIRA, 1953), se deu conta de que aos "gentios" não restara nem mesmo o sertão. Diante disso, tomou para si a missão de povoar esse lugar e se juntou aos cidadãos comprometidos com os ideais republicanos para a condução do projeto. O padre compreendeu a carência de recursos do sertão e se desdobrou em aptidões (CHAVES, 1998): organizou os cultos; abriu o Livro de Tombo da igreja; criou uma banda de música; criou o traçado urbano da vila, traçando in loco as ruas; vendeu as terras doadas à igreja em "datas" de 25 x $25 \mathrm{~m}$, ampliando o espaço urbano; atraiu imigrantes, formando a colônia italiana com profissionais da saúde, da construção civil e do vestuário; criou uma escola; construiu e vendeu casas. Sua obra levou Teixeira (1953) a afirmar que sua participação foi um passo decisivo para o futuro do lugar. Sendo assim, na virada do século, Pe. Ângelo Tardio Bruno podia comparar favoravelmente a vila republicana atual com a antiga corrutela monarquista que conhecera.

No alvorecer do século XX, a vila já estava bem crescida e era assim constituída: Largo da Igreja, Rua do Comércio, Rua

6 Como consta no Livro de Carta de Aforamento. Fonte: Centro de Pesquisa, Documentação e Memória do Pontal (CEPDOMP) da Faculdade de Ciências Integradas do Pontal (FACIP) da Universidade Federal de Uberlândia (UFU). 
da Matriz, Rua 24 de Maio, Rua São José, Rua Antônio Pedro Guimarães, um rego d'água e uma lagoinha. As ruas eram ainda salpicadas de casas cobertas de capim, e os arrabaldes repletos de pastagens e de chácaras, mas o casario em alvenaria coberto de telhas já era em grande número e mudava a feição da vila (TEIXEIRA, 1953; CHAVES, 1984). O comércio se expandia, a vida social em torno da igreja e do Largo da Matriz era efervescente. O proprietário rural já habitava a vila entrelaçando espaço rural e urbano na formação de uma trama têxtil que favoreceria as mudanças socioeconômicas do lugar.

Villa Platina vivenciava o início do processo de urbanização e com ele uma nova sociabilidade que envolvia aspectos modernos evocados pelo governo central ao longo do século XIX. Essa nova sociabilidade impunha à "boa sociedade" valores oriundos do mundo europeu ao privilegiar a difusão da moda, ou melhor, a distinção social expressa nos modos de vestir. $O$ primeiro recenseamento populacional da vila autônoma nos permite visualizar essa distinção intrínseca na trama têxtil da sociedade platinense.

\section{Recenseamento de 1904}

Este estudo analisa o documento oficial do recenseamento da população da então Villa Platina (ITUIUTABA, 1904) e se refere a quatro livros: Livro I, Livro III, Livro VI e a um Livro "Sem Ordem", cujos termos de abertura e de fechamento, de cada um dos livros do conjunto, são datados em 23 de abril de 1904. O recenseador e supervisor do recenseamento foi o pároco local, Ângelo Tardio Bruno. Para o recenseamento foi adotado o "elenco de família" e os dados foram fornecidos ao recenseador pelo chefe da família recenseada ou por um seu representante, sendo também este um chefe de família ${ }^{7}$.

7 Como são os casos de Antônio Pedro Guimarães, que representa 33 famílias, e de Augusto Alves Villela Filho, que representa 21 famílias, ambos no 
Os dados solicitados no recenseamento são: $1 . N^{\circ}$ da família recenseada; 2. $\mathrm{N}^{\circ}$ de ordem do sujeito recenseado; 3 . Nome; 4. Filiação; 5. Idade; 6. Naturalidade; 7. Residência; 8. Estado civil; 9. Sabe ler e escrever; 10. Profissão; 11. Condição e 12. Relação ${ }^{8}$. A relação de cada família recenseada foi assinada pelo recenseador e supervisor dos dados e cada página do livro foi assinada pelo primeiro "Agente Executivo"9 da vila, Augusto Alves Villela, assim como também os termos de abertura e fechamento dos livros. Governo e igreja são envolvidos nos recenseamentos da população desde os tempos do Brasil Colonial até a criação e estabilização das instituições competentes. ${ }^{10}$

Segundo o Instituto Brasileiro de Geografia e Estatística (IBGE), as tentativas de levantamento da população do Brasil são muitas e vêm desde o período colonial, mas aquele considerado o primeiro, por ser o mais significativo, é o Censo Geral do Império ou Recenseamento do Brazil em 1872. A partir de então, a população deveria ser recenseada a cada dez anos. Como referência para o estudo deste recenseamento, os mais significativos são: o de 1872, pela sua importância no contexto dos recenseamentos; o de 1890; e o terceiro, o de 1910.

O documento em análise foi realizado entre o recenseamento republicano de 1900 e o de 1910. O documento não registra a

Livro VI. ITUIUTABA. Livros do Recenseamento Municipal de Villa Platina, no ano de 1904. Fonte: Centro de Pesquisa, Documentação e Memória do Pontal (CEPDOMP) da Faculdade de Ciências Integradas do Pontal (FACIP) da Universidade Federal de Uberlândia (UFU). CD-ROM.

Os dados são organizados em tabelas e cada uma delas ocupa duas páginas de um "livro Ata" de capa dura, cartonado e de cor bege, pintado de marrom. Cada livro tem 100 folhas numeradas. A contagem das famílias e dos sujeitos não é sequencial no conjunto de livros, ou seja, cada livro inicia a contagem a partir do item " 1 ". Id. ibid.

9 Agente Executivo" é a designação dada ao vereador mais votado que exercia as funções hoje equivalentes às de Prefeito na gestão do município.

10 A saber: Diretoria Geral de Estatística, em 1872; Instituto Nacional de Estatística (INE), em 1934; e depois Instituto Brasileiro de Geografia e Estatística (IBGE), em 1938. BRASIL. Instituto Brasileiro de Geografia e Estatística (IBGE). Históricos dos censos. Censos demográficos. Disponível em: Disponível em: <http://memoria.ibge.gov.br/pt/sinteses-historicas/ historicos-dos-censos/censos-demograficos>. Acesso em: 17 jun. 2105. 
origem da solicitação do levantamento. No entanto, o fato de ser ele validado pelo "Agente Executivo" em mandato sugere ter sido promovido pelo governo municipal com a participação da igreja local. À igreja coube a operacionalização do recenseamento.

Sendo esse município emancipado logo após a instituição da República Federativa Brasileira e impulsionado pelo pacto federativo, é provável que a intenção do levantamento tenha sido a de facilitar as deliberações da administração política para fins tributários e administrativos.

\section{A população platinense}

Nos quatro livros, foram recenseadas 1.437 famílias, num total de 9.450 pessoas distribuídas por 35 localidades de residência. $\mathrm{O}$ Livro I e o VI registram as populações de áreas rurais. O Livro III se refere ao recenseamento do distrito de Rio Verde com duas áreas urbanas: sua sede em Campo Bello e o povoado de Monjolinho. O Livro "Sem Ordem" se refere à parte da população de Villa Platina, a sede do município, em plena expansão urbana.

O perfil da população se diferencia de acordo com a localidade em três aspectos que são fundamentais para a nossa análise: naturalidade, profissões e nível de alfabetização.

A "naturalidade" do recenseado é um campo muito significativo no recenseamento, porque nos possibilita compreender os movimentos populacionais: são 4.624 os platinenses e 4.829 os imigrantes (internos e externos), ou seja, os forasteiros superam os nativos em 2,17\%. Em geral, essa população era recentemente imigrada, basicamente, de outras cidades de Minas Gerais ${ }^{11}$ ou de estados como São Paulo e Goiás. No entanto, é significativa a presença de imigrantes oriundos de outros países.

11 Essa população é originária de localidades como Araguary, Araxá, Bagagem, Conceição do Rio Verde, C. Jardim, C. Para, C. Pd. Sucesso, Cadeias, Campanha, D. C. Formoso, D. C. Formozo, Desemboque, Fructal, Monte Alegre, Oliveira, Patrocínio, Piumhy, Ponte Nova, Prata, Rio das Velhas, S. Roque, S. Thomé Lethen, Sabará, Sacramento, Sta. Maria, Três Corações, Uberaba, Uberabinha, Veríssimo" e outras. Nesse campo registra-se a cidade, mas é frequente nominarem somente a região ou o país. ITUIUTABA, 1904. 
Um campo quase sempre vazio é o da "profissão", pois a maioria dos recenseados não declara suas profissões, mesmo sendo adultos e, muitas vezes, preenchendo o campo "relação", como empregados do chefe da família a que se vinculam. No Livro III e no Livro VI, a maioria das mulheres adultas não declarara suas profissões. Neste caso, mesmo quando seus maridos se declaravam lavradores, somente eles preenchem o campo "profissões". Já no Livro I e no Livro "Sem Ordem", a maioria das mulheres declara suas profissões. Estes dois livros se destacam dos outros porque neles encontramos registrada uma variedade de profissões urbanas ${ }^{12}$. Entretanto, mesmo que sejam citadas essas várias profissões, "lavrador" é a profissão predominantemente masculina e "trabalhos domésticos" a profissão feminina por excelência, sobretudo nos Livros I e VI, onde as profissões urbanas desaparecem.

Pelos registros, constatamos que são 1.451 os alfabetizados, 7.937 os analfabetos e o restante não declara seu nível de instrução. Sendo assim, concluímos que somente $15,35 \%$ da população recenseada nesses Livros eram alfabetizados.

Os imigrantes de outras cidades ou regiões do país estão espalhados pela região rural e urbana, enquanto os imigrantes de outras nacionalidades estão concentrados na vila, ou seja, no Livro "Sem Ordem", e são 40 no total. Destes, 19 são italianos, 6 são austríacos com sobrenomes de origem italiana e 6 são turcos. Os demais são: 3 portugueses, 2 africanos, 1 alemão, 1 prussiano, 1 paraguaio e 1 espanhol. Além destes, no Livro VI temos a presença de 2 árabes e de 1 italiano, e, no Livro I, o registro de 1 japonês e de 1 africano. Os imigrantes estrangeiros exercem, em maioria, profissões urbanas.

Esse documento nos permite uma avaliação parcial da população recenseada por dois motivos. O primeiro deles se refere à falta de dados que poderiam favorecer uma análise mais detalhada dessa sociedade, como a "cor de pele", demanda dos censos anteriormente citados. Numa sociedade recém-saída do processo de produção escravocrata, o item "cor de pele" poderia

12 Profissões urbanas, como: agrimensor, marceneiro, carpinteiro, médico, dentista, costureira, tecelã, lavrador, trabalhos domésticos ("do lar"), cozinheira, agricultor, ferreiro, lavadeira, costureira, alfaiate, negociante etc. 
sinalizar a reorganização do trabalho e a posição do negro nessa sociedade, assim como em relação às profissões do vestuário.

Em 10 de janeiro de 1905, Padre Ângelo Tardio Bruno regista o balanço do Recenseamento da Freguesia de Villa Platina e município (ITUIUTABA, 1884-1912), no qual o autor sustenta que foi levantada uma população de 13.237 habitantes, sendo 6.700 homens e 6.537 mulheres (Tabela 1). Um "livro Ata" de 100 páginas, como os livros estudados nesse trabalho, nos permite registrar cerca de 2.500 pessoas. Seriam necessários, então, seis livros para o recenseamento total da população, sendo um deles incompleto. Dessa forma, nos faltariam dois dos livros do conjunto da obra e esse seria o segundo motivo a corroborar para o entendimento das limitações desse documento para uma compreensão precisa da população dessa sociedade, nos limites que um recenseamento pode nos proporcionar.

Tabela 1 - População de Villa Platina de 1872 a 1910.

\begin{tabular}{|l|c|c|c|c|}
\hline \multicolumn{1}{|c|}{ Denominação } & Ano & População Total & Homens & Mulheres \\
\hline Freguezia de São José do Tijuco & 1872 & 2.431 & 1.271 & 1.160 \\
\hline Distrito de São José do Tijuco & 1890 & 5.067 & 2.624 & 2.443 \\
\hline Município de Villa Platina & 1904 & 13.137 & 6.700 & 6.537 \\
\hline Município de Villa Platina & 1910 & 20.882 & - & - \\
\hline
\end{tabular}

Fonte: Censos de 1872, 1890, 1904 e $1910^{13}$.

Organização: Maristela Novaes, 2015.

13 Para essa tabela, foram consultados: Recenseamento do Brazil em 1872, Cf. BRASIL. Recenseamento do Brasil em 1872. Rio de Janeiro: Typ. De G. Leuzinger \& Filhos, s/d. Disponível em: <http://biblioteca.ibge.gov. br/visualizacao/monografias/GEBIS\%20-\%20RJ/Recenseamento do Brazil_1872/Imperio\%20do\%20Brazil\%201872.pdf >. Acesso em: 10 set. $\overline{2015}$; Synopse do recenseamento de 31 de dezembro de 1890, Cf. BRASIL. Ministério da Indústria, Viação e Obras Públicas. Diretoria Geral de Estatística. Brasil. [Constituição (1891)]. Synopse do recenseamento de 31 de dezembro de 1890. Rio de Janeiro: Officina da Estatistica, 1898. Disponível em: <http://www2. senado.leg.br/bdsf/item/id/227299>. Acesso em: 10 set. 2015; Recenseamento Geral do Brasil de 1950, Cf. BRASIL. População do Brazil por municípios e estados (1907-1912). Recenseamento Geral do Brasil (10 de setembro de 1940), Série Nacional (Il volume), Censo Demográfico: população e habitação. Rio de Janeiro: Serviço Gráfico de Geografia e Estatística, 1950. Disponível em: <http://seculoxx.ibge.gov.br/images/seculoxx/arquivos_download/ populacao/1908_12/populacao1908_12v1_082_a_116.pdf>. Acesso em: 10 set. 2015; e ITUIUTABA. Tombo da Matriz de Sāo José. Livro N 1 . Ituiutaba: Matriz de Sao José, 1884-1912. 
Nos quatro livros, as famílias registradas eram, normalmente, muito numerosas. Os "nomes" dos sujeitos recenseados são, predominantemente, de origem portuguesa e, nesses casos, a homonímia é uma recorrência. Muitas vezes os recenseados apresentam somente o nome, sem nenhum sobrenome, sugerindo desconhecerem suas origens. No registro da "filiação" é predominante a paternidade do sujeito e o da maternidade, uma exceção. Em muitos casos a filiação é "desconhecida" ou apenas sugerem essa condição, uma vez que o campo para esta informação permanece em branco. Pela "idade" registrada, podemos constatar que a população menor de idade é muito mais numerosa que a população adulta: no total, são $5.406 \mathrm{e}$ 3.030 , respectivamente. O campo "relação" registra a posição do sujeito recenseado em referência ao chefe da família. A chefia de $88,6 \%$ das famílias é exercida por homens, enquanto $11,3 \%$ seria destinada às mulheres, geralmente viúvas.

Concluímos que, nos livros analisados, a população descrita é rural com nomes predominantemente de origem portuguesa. Pela condição de propriedade, percebemos a proeminência da desigualdade socioeconômica nessa sociedade, pois no campo "condição" o número de proprietários ${ }^{14}$ se restringe a $6,6 \%$ da população. Trata-se de uma população em expansão pelo processo de imigração (interno e externo) e pelas altas taxas de natalidade que registram $57,20 \%$ de menores na população. Nesse universo, $0,19 \%$ da população é composta de profissionais ligados à manufatura de roupas.

\section{As profissões do vestuário na trama têxtil de Villa Platina}

Profissões ligadas ao vestuário são citadas no Livro I, no Livro "Sem Ordem" e desaparecem completamente nos demais livros. Elas se resumem a 14 costureiras, 3 tecelãs, 1 alfaiate e 1 discípulo de alfaiate, num total de 18 profissionais (Tabela 2).

Essas profissões encontram-se estabelecidas na Villa Platina,

14 O termo "proprietário", como aparece no recenseamento, é ambíguo e não especifica o tipo de bem. Por isso, não podemos inferir se a propriedade à qual se refere é um terreno, uma casa na vila ou ainda um imóvel rural. 
no arraial de Monjolinho e na zona rural do município. Dos 18 profissionais levantados, somente 1 costureira e 2 tecelãs são declaradas analfabetas. Todos os outros 15 profissionais ligados às profissões do vestuário se declaram alfabetizados. Numa sociedade basicamente analfabeta, esse é um dado relevante e nos coloca algumas questões: 1. para o exercício da costura nessa sociedade, era fundamental saber ler e escrever?; 2. a proporção de analfabetas no grupo de tecelãs é muito maior do que no grupo de costureiras, o que sugere que, para o exercício da tecelagem, o domínio da leitura era dispensável; e 3. num total de 9.450 indivíduos, por que somente 13 mulheres se declaram costureiras, 3 se declaram tecelãs, 1 se declara alfaiate e 1 se declara discípulo de alfaiate?

Tabela 2 - Profissões do vestuário em Villa Platina em 1904. ${ }^{15}$

\begin{tabular}{|c|c|c|c|c|c|}
\hline $\begin{array}{l}\mathrm{N}^{\circ} \mathrm{de} \\
\text { familia }\end{array}$ & $\begin{array}{l}\mathrm{N}^{\circ} \mathrm{de} \\
\text { ordem }\end{array}$ & Nome & Filiação & Idade & Naturalidade \\
\hline 1 & 4 & $\begin{array}{l}\text { Purdenciana Alves } \\
\text { de Oliveira }\end{array}$ & $\begin{array}{l}\text { Emerenciano Alves de } \\
\text { Andrade }\end{array}$ & 33 & Santa Maria \\
\hline 2 & 14 & Tereza Benta & Felissia (sic.) Maria de Jesus & 25 & Araguary \\
\hline 3 & 18 & Maria Rufina & Rufino da Costa Fagundes & 25 & Villa Platina \\
\hline 20 & 139 & $\begin{array}{l}\text { Mariana Alves do } \\
\text { Nascimento }\end{array}$ & Pedro Alves Correia (sic.) & 62 & Piruy \\
\hline 35 & 211 & $\begin{array}{l}\text { Theodora Candida } \\
\text { de Jesus }\end{array}$ & Pedro Alves Correia (sic.) & 62 & Piruy \\
\hline 46 & 288 & $\begin{array}{l}\text { Etelvina Garcia de } \\
\text { Oliveira }\end{array}$ & José Bernardino de Oliveira & 18 & Villa Platina \\
\hline 48 & 301 & $\begin{array}{l}\text { Rita (?) Garcia de } \\
\text { Oliveira }\end{array}$ & José Bernardino de Oliveira & 33 & Villa Platina \\
\hline 50 & 323 & $\begin{array}{l}\text { Iranta (?) Garcia de } \\
\text { Oliveira }\end{array}$ & José Bernardino de Oliveira & 20 & Villa Platina \\
\hline 70 & 476 & $\begin{array}{l}\text { (?)Iria Maria de } \\
\text { Oliveira }\end{array}$ & Manoel Ferreira Rosa & 60 & Monte Alegre \\
\hline
\end{tabular}

${ }^{15}$ A tabela foi organizada segundo a disposição dos dados no livro. A primeira tabela corresponde à página da esquerda e a segunda, à página da direita. Os dados são lidos da esquerda para a direita, seguindo a linha correspondente, e, para facilitar a leitura, reinserimos os " $n$ s de ordem" dos sujeitos recenseados na segunda tabela. $O$ livro a que se referem vem indicado em (L. 1, Fam. $\mathrm{N}^{\circ}$ $46, N^{\circ} \mathrm{O} .282$ ), sendo L, livro com o $n^{\circ}$ na sequência; livro Fam, família com o $n^{\circ}$ na sequência e " $N^{\circ} \mathrm{O}$ ", o número de ordem do sujeito no livro. 


\begin{tabular}{|c|c|l|l|c|c|}
\hline 72 & 455 & $\begin{array}{l}\text { Maria Gertrudes } \\
\text { das Dores }\end{array}$ & Vicente José Muniz & 41 & Villa Platina \\
\hline 124 & 801 & $\begin{array}{l}\text { Emilia da Fonceca } \\
\text { e Silva }\end{array}$ & João da Fonceca e Silva & 34 & E. de Goyaz \\
\hline 140 & 878 & $\begin{array}{l}\text { Ambrozina da } \\
\text { Silveira Diniz }\end{array}$ & João Alves Ferreira & 27 & E. M. Grosso \\
\hline 157 & 992 & Aldelia Finotte & Theobaldo Finotte & 29 & Italia \\
\hline 184 & 1174 & $\begin{array}{l}\text { Candida de Souza } \\
\text { Monteiro }\end{array}$ & $\begin{array}{l}\text { Antonio Joaquim de Souza } \\
\text { Monteiro }\end{array}$ & 56 & Campo Bello \\
\hline 223 & 1436 & Carmilia Janunzzi & José Antônio Janunzzi & 30 & Prata \\
\hline 108 & 716 & Erinia(?) Simone & Amadio Simone & 32 & Italia \\
\hline 52 & 382 & Miguel Jualianie(?) & Antonio Jualianie(?) & 31 & Italia \\
\hline 52 & 388 & $\begin{array}{l}\text { Antonio Ricardo } \\
\text { Ferreira }\end{array}$ & José Ricardo Ferreira & 21 & Prata \\
\hline
\end{tabular}

\begin{tabular}{|c|l|l|l|l|l|l|}
\hline $\begin{array}{c}\text { No de } \\
\text { Ordem }\end{array}$ & Residência & $\begin{array}{l}\text { Estado } \\
\text { Civil }\end{array}$ & Sabe ler e escrever & Professão & Condição & Relação \\
\hline 4 & $\begin{array}{l}\text { Segundo } \\
\text { Salto }\end{array}$ & Viúva & Sim & Costureira & Proprietária & Sogra \\
\hline 14 & $\begin{array}{l}\text { Segundo } \\
\text { Salto }\end{array}$ & Casada & Sim & Costureira & Proprietária & Esposa \\
\hline 18 & $\begin{array}{l}\text { Segundo } \\
\text { Salto }\end{array}$ & Casada & - & Tecelã & Proprietária & Esposa \\
\hline 139 & Fattoria & Casada & Não & Tecelã & Proprietária & Mãe \\
\hline 211 & Fattoria & Viúva & $\operatorname{Sim}$ & Tecelã & - & Tia \\
\hline 288 & Monjolinho & Solteira & $\operatorname{Sim}$ & Costureira & - & Filha \\
\hline 301 & Monjolinho & Casada & $\operatorname{Sim}$ & Costureira & - & Esposa \\
\hline 323 & Monjolinho & Casada & $\operatorname{Sim}$ & Costureira & - & Esposa \\
\hline 476 & Villa Platina & Viúva & não & Costureira & C. c & Chefe \\
\hline 455 & S.Roza & Viúva & Sim & Costureira & Proprietária & Viúva \\
\hline 801 & Villa Platina & Casada & $\operatorname{sim}$ & Costureira & - & Esposa \\
\hline 878 & Villa Platina & Casada & $\operatorname{sim}$ & Costureira & - & Esposa \\
\hline 992 & Villa Platina & Casada & $\operatorname{sim}$ & Costureira & - & Esposa \\
\hline 1174 & Villa Platina & Solteira & $\operatorname{sim}$ & Costureira & - & Filha \\
\hline 1436 & S. Lourenço & Casada & $\operatorname{sim}$ & Costureira & - & Esposa \\
\hline 716 & Villa Platina & Cazada & $\operatorname{sim}$ & Costureira & - & Esposa \\
\hline 382 & Villa Platina & Solteiro & $\operatorname{sim}$ & Alfaiate & C. c & Chefe \\
\hline 388 & Villa Platina & Solteiro & $\operatorname{sim}$ & & & Discipulo \\
\hline & & & & & \\
\hline
\end{tabular}

Fonte: Livro I e "Sem Ordem" do Recenseamento Municipal de Villa Platina em 1904. Transcrição: Maristela Novaes, 2015. 
das costureiras serem da mesma família, a de José Bernardino de Oliveira (L. 1, Fam. $N^{\circ} 46, N^{\circ}$ O. 282). Também duas das três tecelãs são irmãs, filhas de Pedro Alves Correia (L. 1, p. 07 e 11). Estes dados nos colocam ainda outra questão: como se adquiriam os conhecimentos necessários às profissões da costura e da tecelagem? Eram profissões cujos conhecimentos se adquiriam em família?

É relevante, na leitura dos dados, o fato de três das profissionais da costura residirem na região rural: Segundo Salto, S. Lourenço e duas em fazendas não nominadas. Quatro outros profissionais residem no povoado de Monjolinho, pertencente ao distrito de Rio Verde. Oito deles residem na sede do município, ou seja, em Villa Platina. Duas das tecelãs que aparecem no recenseamento residem em fazendas. Que relação pode haver entre essas profissões e os lugares de residências dos profissionais que as exercem?

O movimento de imigração que percebemos na população em geral se confirma também na população ligada às profissões do vestuário. Desse universo de profissionais, somente quatro são naturais de Villa Platina e estão no grupo das mais jovens. Sete deles vêm de cidades do próprio estado. Uma vem de Campo Bello, sede do distrito de Rio Verde. Dois vêm de estados próximos: Goiás e Mato Grosso. Três profissionais são imigrantes italianos e uma descende de pai italiano.

A desigualdade socioeconômica que caracteriza a sociedade em geral está presente também entre os nativos, entre os imigrantes de cidades e regiões do Brasil, assim como entre os imigrantes italianos do grupo de profissionais do vestuário. Quatro costureiras são proprietárias; quatro não são "proprietários", mas estão ligadas a um "proprietário" por matrimônio ou parentesco; e o restante não é proprietário e não tem relações de parentesco com proprietários. Proprietários ou não, a manufatura de roupas se faz a partir da matéria-prima.

O comércio abastece as profissões do vestuário com matériaprima e informações de moda e de técnicas de construção de roupas. No recenseamento, encontramos 22 negociantes e 4 
ajudantes de comércio. Não existe registro de comerciante. Como em outros aspectos, a terminologia não nos favorece a compreensão das posições dos sujeitos quanto ao seu papel no comércio. Entre os comerciantes levantados, podemos ver a presença de nomes portugueses, de imigrantes italianos, assim como de sírio-libaneses. Portanto, diferentes origens se entrelaçam em diversas atividades ligadas à manufatura de roupas.

\section{As habilidades da gente do sertão}

O Recenseamento Geral do Brasil de 1872 registra como profissões ligadas ao vestuário: "costureiras", "operários em tecido" e "operários de vestuários". Não registra alfaiates e não categoriza os "operários em tecido" e "operários de vestuários". Para o estado de Minas Gerais, ele registra como costureiras 124.633 mulheres, 7.904 "operários em tecido" e 838 "operários de vestuário". Em São Paulo, temos: 29.082 costureiras, 10.256 "operários em tecido" e 1.659 "operários de vestuários". E, em Goiás: 8.984 costureiras, 9.829 "operários em tecido" e 463 "operários de vestuários".

O Triângulo Mineiro teve seu processo de povoamento vinculado à distribuição das cartas de sesmarias a partir do início do século XIX. Lara (1912, p. 222) afirma que "as raízes da Farinha Podre nunca foram mineiras, mas sim resultado de uma mistura cultural herdada das províncias de São Paulo, Goiás e Minas", o que se confirma nos dados do recenseamento e sugere que a cultura da tecelagem e das práticas de manufatura de roupas tenha se disseminado na região ao longo da "marcha para o oeste".

Em 1842, trinta e dois anos após o início de povoamento da região, a presença de ovinos, entre os animais de criar, e de rodas de fiar, na relação de móveis do inventário de João Inácio Franco, é um claro indício de que havia em sua propriedade uma razoável produção de panos de lã (LARA, 1912). No elenco do inventário de Ignácio José Muniz, feito por sua esposa Purcina 
Maria de Jesus em 1877, consta "a presença de uma roda de fiar velha e de uma máquina de costura de pé” (LARA, 1912, p. 29), sinalizando a produção têxtil e a atividade de costura no ambiente rural. O primeiro inventariado é situado na fazenda dos Bahús e o segundo, na fazenda Santa Bárbara, ambas em Villa Platina.

A confirmar a evidência da cultura têxtil e da costura, Petronio Rodrigues Chaves (1953, p. 46) afirma que, em São José do Tijuco, o algodão era cultivado para abastecer a indústria caseira de fiação nas rodas e a tecelagem nos teares primitivos, onde se fabricavam tecidos de algodão com os quais "se confeccionavam calças e camisas para homens, saias para as mulheres, rêdes, mantas e cobertas para as camas".

O recenseamento de 1872 registra a costura como sendo uma profissão eminentemente feminina. Além disso, mesmo não desenvolvendo a atividade como uma profissão, as mulheres costuravam as roupas da família para contribuir com a economia doméstica, sendo este o escopo das disciplinas de "trabalhos manuais" nas escolas católicas do período. A atividade de costura e a de tecelagem também podia ser exercida como um complemento às atividades domésticas, como ilustra a personagem Germana do romance de Chaves. Segundo o autor (CHAVES, 1998, p. 214), "Germana cuidava dos trabalhos caseiros e, nas folgas, sentavase à roda, fiando algodão, que vendia aos novelos".

Durante o processo de povoamento, escravos e terras foram os pilares da riqueza da maioria dos fazendeiros do "Sertão da Farinha Podre" e, mesmo sendo a agricultura a base da economia, um instrumento importante como o arado era por eles ignorado. Esse atraso tecnológico limitava as áreas de plantio que eram, em média, 7,7\% menores que os campos usados para o pastejo.

Lara (2012, p. 213) afirma que "o mesmo não se pode dizer dos instrumentos empregados na indústria doméstica têxtil, tais como teares, urdideiras, descaroçadores, fusos, rocas e cardas". A tecelagem é uma herança do passado colonial das Minas Gerais, que se constituiu numa indústria doméstica têxtil que, pelo grande número de mulheres e meninas nela envolvidas, ultrapassou com intensidade a produção de autoconsumo em toda 
a província. Segundo Lara (2012), essa indústria "absorvia grande parte da mão de obra feminina, que preponderava e controlava os métodos e as técnicas de produção de fios e panos, quer a mulher fosse livre ou escrava". O autor afirma que, pelos quatro cantos da província, o cenário era sempre idêntico em qualquer fogo: "sob o mesmo teto [...] fiandeiras e tecedeiras, mulheres livres e escravas, viúvas e casadas, mães e filhas, todas juntas, comprometendo-se nas várias etapas do intrincado trabalho artesanal de fiação e tecelagem" (LARA, 2012).

O universo de profissionais do vestuário em Villa Platina se completa com 3 profissionais levantados nas citações bibliográficas de historiadores e memorialistas do lugar. São eles: "Pedro Prescialiano", alfaiate e músico; "Inhá, costureira para homens" (CHAVES, 1984, p. 352-353); e "Zeca Alfaiate" (TEIXEIRA, 1953, p. 244). Com isso, chegamos a 22 profissionais, sendo: 3 tecelãs, 15 costureiras, 3 alfaiates e 1 discípulo de alfaiate.

Podemos aferir que as profissões do vestuário estavam distribuídas no espaço urbano e rural, sendo o maior número de costureiras e os alfaiates concentrados na sede do município: Villa Platina. As origens desses profissionais traziam, certamente, experiências e formações distintas, heterogêneas entre si, uma vez que a tecelagem, a costura e a modelagem implicam inúmeros procedimentos e técnicas que podem conviver contemporaneamente.

\section{Tradição e modernidade no tecer panos e fazer roupas}

A costura, que transforma o material têxtil, foi tradicionalmente realizada com técnicas manuais, mas, em meados do século XIX, sofreu uma grande revolução tecnológica: o surgimento da costura mecânica. Essa se tornou possível graças ao aperfeiçoamento da máquina de costura e das formas de comercialização desse produto - feitos por Issac Singer nos E.U.A. a partir de 1853 que o introduziram nos espaços domésticos de grande parte do mundo ocidental e oriental.

A costura mecânica é uma atividade complexa na medida 
em que a costureira deve desenvolver a coordenação motora para, simultaneamente, operar a máquina e manusear os tecidos. Considerando os modelos mais primitivos, como os das primeiras máquinas, a costureira deve acionar e manter em movimento a manivela ou os pedais, ao mesmo tempo em que organiza e direciona as diversas folhas de tecido em costuras de linhas curvas, retas ou quebradas, numa infinidade de arranjos. Nesse sentido, as costureiras do "Sertão da Farinha Podre", com toda a falta de recursos do lugar, demonstraram maior disponibilidade para a absorção de novas ferramentas e de novas técnicas da atividade de costura do que os lavradores locais em suas atividades, pois, como vimos, a máquina de costura já era presente nas listas de inventários dos finais do século XIX.

No recenseamento (ITUIUTABA, 1904), o vazio abissal no campo das "profissões" é um fato. Segundo Bloch (2001, p. 95), "à medida que a história foi levada a fazer dos testemunhos involuntários um uso cada vez mais frequente, ela deixou de se limitar a ponderar as afirmações [explícitas] dos documentos". Sendo essa uma sociedade patriarcal, agropastoril, os dados do recenseamento em estudo foram, quase sempre, fornecidos pelo chefe de família. Numa tentativa de desvendar as informações possivelmente ocultadas pelos chefes de família, buscamos algumas explicações para lacunas presentes no censo. A primeira delas é que o desprezo pelos ofícios mecânicos e o temor da degradação possuíam raízes assentadas no antigo regime de produção, o sistema escravista, "do qual saíram em abundância os 'negros de ganho', o que contribuía para acentuar o preconceito contra o trabalho manual externado pelas pessoas de melhor condição social" (MALERONKA, 2007, p. 31). O segundo é a necessidade de os indivíduos dessa sociedade exercerem variadas funções e, com isso, serem impossibilitados de se especializarem em determinadas atividades. No caso das mulheres, essa lacuna também pode evidenciar o desdém dos patriarcas pelas atividades femininas, exercidas quase sempre como tarefas ordinárias resultantes de uma educação informal adquirida em família e através da cultura oral (LARA, 2012).

Essa cultura de omissão das atividades relacionadas à 
manufatura de roupas em geral, e às atividades femininas em particular, na vila, pode ser flagrada na comparação das publicações dos municípios produzidas pelos "Agentes Executivos" da cidade do Prata e de Villa Platina no Rio de Janeiro. Enquanto a primeira localidade divulgava suas modistas e alfaiates (ALMANAK, 1903, p. 1259-1260), Villa Platina privilegiaria as atividades ligadas às profissões masculinas e ao mundo rural (ALMANAK, 1909, p. 103-105).

As técnicas de modelagem e de costura, masculina e feminina, tiveram grande desenvolvimento nos séculos XVIII e XIX (TECNICUS, [1948?]). No que se refere à modelagem de roupas, a técnica geométrica foi a que, primeiramente, melhor se adequou aos métodos de produção industrial, tornando-se com isso hegemônica. Essa técnica, que é embasada no desenho geométrico, exigia, como conhecimento, além do próprio desenho, as equações básicas da matemática e o manuseio de utensílios específicos para o traçado de moldes personalizados. Os muitos métodos resultados dessa técnica foram criados, sobretudo, na França e na Inglaterra, e eram disseminados no Brasil.

O Colégio N. Sra. das Dores de Uberaba, dominicano de origem francesa, que também cuidava da educação das moças da aristocracia rural dessa região, oferecia entre as suas disciplinas: "Arithmetica, Systema métrico, Lingua (sic.) Franceza [...] e também trabalhos manuaes próprios de uma senhora como: costura, crochet, bordados, etc." (SILVA, 1885, p. 3). Além da alfabetização, essas três disciplinas citadas podiam facilitar o acesso ao conhecimento das novas técnicas divulgadas nas revistas de moda nacionais e importadas que circulavam no país e na região. Uma disciplina a tratar exclusivamente do sistema métrico evidencia as dificuldades na adoção desse sistema, que havia sido criado na França em 1790, e que fora transferido para a fita métrica em meados do século XIX. Talvez a complexidade das novas técnicas de modelagem seja um fator a determinar um grau mínimo de alfabetização para afrontar o exercício da costura como uma profissão, se a compreendemos ligada à modelagem personalizada.

A tecelagem, nos seus procedimentos mais rudimentares, 
pode estar ligada aos conhecimentos embasados, sobretudo, na tradição oral, e por isso talvez dispense a alfabetização tão limitada naquela região. No documento em análise, o registro de quatro costureiras descendentes do mesmo pai, assim como de duas tecelãs de outro, é evidência de que essas são profissões cujos conhecimentos podiam ser adquiridos em família, assim como também a alfabetização. Segundo Chaves (1984), antes de ir para a escola formal prosseguir seus estudos, ele e sua irmã Alice estudaram as primeiras letras e as quatro operações em Campo Bello com a irmã mais velha, Etelvina, recém-diplomada em Uberaba.

Outro meio de aquisição informal de conhecimentos de costura pode ser sugerido pela relação de Miguel Jualianie ${ }^{16}$, de 31 anos (L. s/o., fam. $n^{\circ} 52, n^{\circ}$ o. 382), e de Antônio Ricardo Ferreira (L. s/o., fam. $n^{\circ} 52, n^{\circ}$ o. 388), de 21 anos. Este último é o único discípulo da profissão encontrado no documento e sugere a permanência da aprendizagem artesanal no modelo em que o mestre ensinava o ofício ao jovem aprendiz, "em sua própria oficina, com seus próprios instrumentos e até mesmo morando em sua casa" (CUNHA, 2005, p. 2.). Além disso, ela merece destaque porque Miguel Jualianie é o único profissional que declara ter um ajudante, o que sugere um volume de produção considerável em relação aos demais profissionais do vestuário.

A negação da relevância da atividade de costura pelos platinenses não encontraria eco entre os pratenses. De 1904 a 1907, a administração da cidade do Prata, da qual a vila havia se emancipado, publicaria, no Rio de Janeiro, sua relação de profissionais ligados à produção de vestuário (SAUER, p. 1259-1260; SAUER, 1911, p. 140). Dela fizeram parte, por seis anos, as alfaiatarias: Chic Universal, de Miguel Giuliani; Tesoura Mineira, de Antenor Soares da Costa; e o alfaiate José Vida de

16 Miguel Jualianie(?) poderia ser Michele Giuliani ou ainda Miguel Giuliani, homônimo de seu colega de profissão instalado no Prata. SAUER, A. Almanak Laemmert: Almanak Administrativo, Mercantil e Industrial do Rio de Janeiro: Estado de Minas Geraes. Rio de Janeiro: Companhia Typographica do Brazil, 1904. Disponível em: <http://memoria.bn.br>. Acesso em: 20 set. 2015. 
Camargos. No que se refere à confecção de roupas femininas, o mesmo anúncio divulgava o trabalho das modistas: Abbadia Maria de Jesus, Francisca Moreira da Costa, Maria Clemencia de Novaes, Philomena Moreira da Costa e Vitalina Angelica da Silva. Às tecelãs, não sendo citadas em nenhum dos anúncios, coube o anonimato.

As diferenças entre esses profissionais, entre os inúmeros procedimentos e entre técnicas na manufatura de roupas certamente conviviam com maior ou menor intensidade nessa sociedade de núcleos urbanos pequenos, carente de recursos e de população pobre e rarefeita espalhada pelas imensas áreas de produção rural. Os núcleos rurais, no entanto, se ligavam aos centros urbanos, onde as mudanças fluíam mais rápidas em função do grande tráfego de pessoas, produtos e conhecimentos, próprios de uma sociedade em expansão urbana.

Uma das modalidades comerciais que permitiam essas ligações pode ser compreendida na experiência de Pedro Rodrigues Chaves que atuou nessa região, primeiro, como mascate e, posteriormente, como comerciante. Como mascate, por muitos anos ele aprontou seus cargueiros, acondicionando as mercadorias nas bruacas, percorrendo o sertão, viajando de "fazenda em fazenda, onde fazia pião, para atender aos moradores da vizinhança. Abria as bruacas repletas de tecidos, caixas de armarinhos, calçados, enfeites, bugigangas" (CHAVES, 1984, p. 92). Feito o patrimônio necessário, Pedro Rodrigues Chaves abriu loja própria e passou à condição de comerciante em Campo Bello e, posteriormente, em Ituyutaba. As mercadorias eram adquiridas em Uberaba. Tradicional centro comercial, de relevância regional, essa cidade oferecia uma significativa rede comercial. Dela faziam parte atacadistas em produtos de vestuário, como: a Casa Caldeira, a Casa Especial, a Meirelles Carvalho \& Cia., a Sobral \& C., a Vasconcelos, a Couto \& Comp. etc. (RIBEIRO, 1895, s/p.). Lojas como o Empório Barateza, integrante dessa rede, propagavam, ainda em 1888,

Ter recebido o mais esplendoroso sortimento do ano, escolhido 
na côrte, S. Paulo e Santos por um dos sócios da casa que ali foi expressamente para comprar o que houvesse de superior, não só em qualidade de gêneros, gostos, padrões, novidades, como também em barateza de preços. (SILVA, 17 out. 1885, p. 4).

Esses atacadistas abasteciam também as tradicionais casas comerciais de São José do Tijuco, entre as quais: a casa comercial de José Martins Ferreira (1864), a de Capitão José Flausino Ribeiro (1870), a do Capitão Jerônimo Martins de Andrade (1882), a de Manuel Caetano de Novais (1883), a de Lica Martins e a de Nagib Yunes (CHAVES, 1984). Em 1909, vemos uma evidência das mudanças e da expansão no comércio de Villa Platina, na divulgação de seus estabelecimentos comerciais especializados em "fazendas, ferragens, armarinhos (vendendo 60 contos para cima): Ferreira \& Avelar, Junqueira \& Andrade, Junqueira \& Padua, Maria Noyane, Marques \& Oliveira e Tito Chaves \& C.a" (SAUER, 1909, p. 1-104).

A presença do estrangeiro, em especial da colônia italiana e de alguns sírio-libaneses, no âmbito das práticas de construção da roupa e no comércio, pode ter agregado mudanças, como já se evidenciava na arquitetura, no urbanismo, na vida sociocultural e administrativa de Villa Platina. No caso das mudanças relativas ao sistema de vestuário, ela se fazia sentir a partir do eixo de ligação comercial da vila com Rio de Janeiro, com São Paulo e com Santos, passando por Uberaba ou por Uberabinha, que faziam o entreposto comercial. Todos esses polos já contavam com a interferência do contingente de imigrantes europeus, provocando mudanças em todas as esferas do sistema de vestuário. Essas inovações chegavam ao sertão e conviviam com os modos tradicionais de comercializar e de construir roupas, seja pela inserção da diversidade de matérias-primas, de formas e de tipologia de roupas, como também das técnicas que viabilizavam suas materialidades. 


\section{Arrematando o tecido}

Apesar de nos faltar dados para uma leitura mais rigorosa, esse recenseamento (ITUIUTABA, 1904) nos possibilita a visualização de uma sociedade rural, com uma população basicamente analfabeta em crescimento acelerado e em profunda transformação sociocultural motivada por fatores internos e externos.

A partir dos dados levantados nessa pesquisa, concluímos que os profissionais envolvidos nas atividades de manufatura de roupas em Villa Platina, no final do século XIX e na primeira década do século XX eram predominantemente mulheres, alfabetizadas, nativas ou originárias de outras cidades, estados ou países e de distintas classes sociais. Verificamos que as informações circulavam rapidamente entre estes profissionais, que faziam uso de novas técnicas e máquinas, por vezes, as mais modernas da época, em contraste com o setor agrícola produtivo que não se modernizava na mesma velocidade, ainda que essa sociedade fosse predominantemente rural com economia embasada na agropecuária.

A circulação de informações relativas aos saberes específicos da construção de roupas (modelagem e costura) era promovida em parte por intermédio da cultura familiar, em parte pelo ensino dado às mulheres nas escolas católicas, mas também pela experiência trazida pelos imigrantes brasileiros e estrangeiros que vinham de centros urbanos maiores cujos conhecimentos da manufatura das roupas se beneficiavam de longa e aprimorada tradição. No entanto, além da tradição, muitos imigrantes europeus já tinham conhecimento de novas tecnologias decorrentes da revolução industrial da qual o sistema de moda é um produto.

Como exposto, a atividade da costura na virada do século em Villa Platina já era praticada com fins comerciais e não apenas motivada pelo autoconsumo. Esse corresponde ao período em que as mulheres adentravam o mercado de trabalho e a costura foi uma possibilidade profissional para muitas delas (MALERONKA, 2007). Diante da diversidade de formas e de materiais, destacar- 
se no ambiente profissional implicava que cada artesão se empenhasse em explorar ao máximo suas habilidades e se mostrasse informado sobre as mudanças nos feitios e nas técnicas empregadas na construção de roupas (MALERONKA, 2007).

Nesse contexto, o comércio exercia um papel fundamental, pois ele se entrelaçava à manufatura de roupas, fornecendo matérias primas, instrumentos, máquinas, informações de moda e impulsionando a assimilação de novas técnicas empregadas nos feitios. Era ele o agente de ligação entre a vila e os grandes centros de distribuição de mercadorias.

O resultado do levantamento da população proporcionou o dimensionamento do analfabetismo e da significativa parcela de menores na população local. Este fator pode ter determinado a conjunção de esforços das autoridades administrativas e da comunidade para resolver a questão da educação. Observamos que, entre as deliberações da administração política da vila, posteriores ao levantamento, a construção de um edifício destinado à criação do Grupo Escolar Villa Platina inaugurou o ensino formal primário na vila em 1910. O manual intitulado $O$ ensino em Minas Gerais no Tempo da República (1964) apresenta o currículo instituído nos grupos escolares do período, e, neste, as disciplinas elencadas, como: corte costura, ensino de matemática/ aritmética, geometria e desenho, francês, trabalhos manuais, costura e trabalhos de agulha para as meninas (MOURÃO, 1962). Essas disciplinas proporcionavam uma formação que favorecia a assimilação dos conteúdos dos novos métodos de modelagem geométrica embasada no cientificismo e no positivismo (TECNICUS, [1948?]), na mesma medida em que impulsionariam o consumo de informações de moda e de técnicas de manufatura divulgadas nas revistas de moda nacionais e francesas em circulação no país.

O diálogo estabelecido por intermédio das fontes e do referencial teórico possibilitou, a priori, concluir que o contraste do rural com o urbano, do saber formal com o informal, do conhecimento da classe dominante com o da classe menos favorecida, da cultura local e as dos imigrantes, constituiu a 
trama têxtil de Villa Platina. A trama, no entanto, se constitui de direitos e avessos. Nessa perspectiva, a relação dessa sociedade com o seu sistema de vestuário se estabelece pelo lado direito, aquele que implica a norma, o oficial, o instituído, mas também pelos vazios - a invisibilidade das profissões, especialmente as femininas, e as ambiguidades das relações sociais -, os laços pessoais que escondem as relações de exploração do trabalho que constituem o avesso da trama.

\section{Bibliografia}

ALMANAK administrativo, mercantil, e industrial do Rio de Janeiro. Rio de Janeiro, RJ: Typ. Universal de Laemmert, 1844- . Disponível em: $<$ http://bndigital.bn.br/acervo-digital/almanak-administrativo-mercantilindustrial-rio-janeiro/313394>.

BLOCH, Marc. Apologia da história ou o ofício de historiador. Rio de Janeiro: Zahar, 2001.

BRASIL. Instituto Brasileiro de Geografia e Estatística. Históricos dos censos. Censos Demográficos. Disponível em: <http://memoria.ibge.gov. $\mathrm{br} / \mathrm{pt} /$ sinteses-historicas/historicos-dos-censos/censos-demograficos>. Acesso em: 17 jun. 2105.

BRASIL. Ministério da Indústria, Viação e Obras Públicas. Diretoria Geral de Estatística. Synopse do recenseamento de 31 de dezembro de 1890. Rio de Janeiro: Officina da Estatistica, 1898. Disponível em: <http:// www2.senado.leg.br/bdsf/item/id/227299>. Acesso em: 10 set. 2015.

BRASIL. População do Brazil por municípios e estados (1907-1912). Recenseamento Geral do Brasil ( $1^{\circ}$ de Setembro de 1940), Série Nacional (II volume), Censo Demográfico: população e habitação. Rio de Janeiro: Serviço Gráfico de Geografia e Estatística, 1950. Disponível em: <http://seculoxx.ibge.gov.br/images/seculoxx/arquivos_download/ populacao/1908_12/populacao1908_12v1_082_a_116.pdf > . Acesso em: 10 set. 2015. 
BRASIL. Recenseamento do Brasil em 1872. Rio de Janeiro: Typ. De G. Leuzinger \& Filhos, s/d. Disponível em: <http://biblioteca.ibge.gov. br/visualizacao/monografias/GEBIS\%20-\%20RJ/Recenseamento_do_ Brazil_1872/Imperio\%20do\%20Brazil\%201872.pdf>. Acesso em: 10 set. 2015.

CHAVES, Camilo. Caiapônia: romance da terra e do homem do Brasil Central. Ituiutaba: Gil Editora, 1998.

CHAVES, Petronio Rodrigues. A loja do Osório. Ituiutaba: Edição do autor, 1984.

CHAVES, Petronio Rodrigues. Evolução Agrária do Município de Ituiutaba. Revista Acaiaca, Belo Horizonte, 1953.

CUNHA, Luiz Antônio. O ensino de ofícios artesanais e manufatureiros no Brasil escravocrata. São Paulo: Editora UNESP; Brasília, DF: Flasco, 2005.

DONNANNO, Antonio. Modabolario: storia del costume, tessuti e tessitura, tecniniche sartoriali, acessori e stilisti. Milano: Ikon Editrice, 2011.

ITUIUTABA. Livro de Carta de Aforamento. Ituiutaba: Centro de Pesquisa, Documentação e Memória do Pontal (CEPDOMP) da Faculdade de Ciências Integradas do Pontal (FACIP) da Universidade Federal de Uberlândia (UFU). CD-ROM.

ITUIUTABA. Livros do Recenseamento Municipal de Villa Platina, no ano de 1904. Livros I, III, VI e "Sem Ordem". Ituiutaba: Centro de Pesquisa, Documentação e Memória do Pontal (CEPDOMP) da Faculdade de Ciências Integradas do Pontal (FACIP) da Universidade Federal de Uberlândia (UFU). CD-ROM.

ITUIUTABA. Tombo da Matriz de São José. Livro № 1. Ituiutaba: Matriz de São José, 1884-1912. Arquivo da Catedral de São José.

LARA, Mário. A saga da família Franco: das ribeiras do Rio das Mortes Pequeno aos confins de São Simão. Ituiutaba: Edição do Autor, 2012.

MAELERONKA, Wanda. Fazer roupa virou moda: um figurino de ocupação da mulher (São Paulo 1920-1950). São Paulo: Editora Senac, 2007. 
MINAS GERAIS. Album Chorographico. 1927. Disponível em: <http:// www.albumchorographico1927.com.br>. Acesso em: 15 jul. 2015.

MOURÃO, Paulo Krüger Corrêa. O ensino em Minas Gerais no tempo da República. Belo Horizonte: Ed. do Centro de Pesquisas Educacionais de Minas Gerais, 1962.

MUNIZ, Edson Angelo. Família Muniz: tronco do Triângulo Mineiro. Ituiutaba, 2002.

RIBEIRO, D.; COSTA, A. Almanach Uberabense. Rio de Janeiro: Alexandre Ribeiro \& C. 1895. Arquivo Público de Uberaba.

SAUER, A. Almanak Laemmert: Almanak Administrativo, Mercantil e Industrial do Rio de Janeiro: Estado de Minas Geraes. Rio de Janeiro: Companhia Typographica do Brazil, 1904. Disponível em: <http:// memoria.bn.br/DocReader/docreader.aspx?bib=313394\&pasta=ano\%20 190\&pesq=>. Acesso em: 20 set. 2015.

SILVA, Joaquim Antônio Gomes da. Monitor Uberabense, Uberaba, 17 de out. 1885. Disponível em: <http://memoria.bn.br/DocReader/DocReader. aspx?bib=817031\&PagFis=7\&Pesq=>. Acesso em: 18 set. 2015.

TECNICUS. Enciclopedia "la moda maschile": ad uso del tagliatore sarto da uomo. 12 ${ }^{a}$ Edizione. Milano: Ed. La Moda Maschile, ([1948?]).

TEIXEIRA, Edelweiss. A evolução histórica de Ituiutaba (1810-1902). Revista Acaiaca, Belo Horizonte, 1953.

Recebido em novembro de 2015.

Aprovado em outubro de 2016. 